\title{
REVIEW
}

\section{Micropurification techniques in the analysis of amyloid proteins}

\author{
B Kaplan, S Shtrasburg, M Pras
}

J Clin Pathol 2003;56:86-90

This review describes the different microtechniques developed for the extraction and purification of amyloid proteins from small specimens of fresh and formalin fixed tissues. These procedures differ with respect to solvent type, extraction conditions, and protein purification strategy. The advantages and disadvantages of the different microtechniques are discussed by taking into consideration tissue type (fresh of fixed) and size, amyloid type, and its content in the tissue. The review demonstrates the applicability of these techniques for the immunochemical and chemical characterisation of amyloid in different clinical forms of amyloidosis and in experimental small animal models. The clinical value of the applied microtechniques and their importance in the study of the pathogenesis of amyloid related diseases are outlined.

See end of article for authors' affiliations .....................

Correspondence to: Dr B Kaplan, Heller Institute of Medical Research, Sheba Medical Centre, Tel Hashomer 52621, Israel; roman@taro.co.il

Accepted for publication 13 September 2002
T he development of small scale protein purification techniques is dictated by the need to analyse biological samples that are available only in extremely small quantities. Such techniques are also needed for the biochemical examination of amyloid proteins contained in either diagnostic biopsy specimens, small amounts of available postmortem material, or the tissues of small animals with experimentally induced amyloidosis. ${ }^{1}$

"At least 20 different amyloid fibril proteins have been described, many of which are associated with distinct clinical forms of amyloidosis"

Amyloidosis is a destructive pathological condition that occurs as a primary disorder or in association with other diseases and is characterised by the deposition of amyloid in various body tissues and organs. Amyloid deposits found in different clinical forms of amyloidosis share common morphological and tinctorial properties. Amyloid consists of parallel arrays of rigid fibrils that have a $\beta$ pleated sheet configuration, and shows a typical green birefringence in histological sections stained with Congo red and viewed under polarised light. It is composed largely of protein fibrils (amyloid fibrils), together with other non-fibrillar proteins, predominantly glycosaminoglycans, proteoglycans, and serum amyloid P component. The non-fibrillar proteins are ubiquitous minor components of the deposits, tightly associated with fibrils. However, in spite of such common features, amyloid deposits are strikingly different with respect to the chemical nature of their major fibrillar protein constituents. To date, at least 20 different amyloid fibril proteins have been described, many of which are associated with distinct clinical forms of amyloidosis. $^{2-4}$ The AA protein, an N-terminal fragment of the apolipoprotein and acute phase reactant serum amyloid A protein (SAA), forms amyloid fibrils that are found in association with reactive systemic amyloidosis and familial Mediterranean fever. Several SAA isotypes are known to be involved in the pathogenesis of human amyloid A protein (AA) amyloidosis. In primary AL amyloid, associated with myeloma and other malignant B cell and plasma cell dyscrasias, the fibrils are derived from either whole monoclonal immunoglobulin light chain fragments $(\kappa$ or $\lambda$ subtype) or fragments thereof. Normal wild-type transthyretin (TTR) forms the amyloid fibrils (ATTR) in senile systemic amyloidosis, whereas over 70 genetic variants of TTR are associated with familial amyloid polyneuropathy. Amyloid $\beta$ peptide $(A \beta)$, a 39 to 42 amino acid residue peptide released from an intramolecular segment of the transmembrane cell surface protein amyloid $\beta$ precursor protein $(\mathrm{A} \beta \mathrm{PP})$, is a major fibril protein found within neuritic and diffuse plaques in the brains of patients with Alzheimer's disease (AD) and Down's syndrome. With few exceptions, ${ }^{56}$ most amyloid fibril proteins are whole or $\mathrm{N}$-terminal fragments of intact precursor proteins.

Because amyloidosis represents a very heterogenous group of diseases associated with the deposition of chemically distinct amyloid fibril proteins, the precise chemical and immunochemical identification of these proteins has diagnostic and therapeutic importance. This is especially true in cases with a presumptive diagnosis of AL amyloidosis: clinical manifestations in AL amyloidosis are extremely heterogeneous, and some of the characteristic patterns of organ involvement are indistinguishable from those in familial amyloid polyneuropathy and

Abbreviations: $A A$, amyloid protein $A ; A \beta$, amyloid $\beta$ protein or peptide; $A \beta P P$, amyloid $\beta$ protein precursor; $A D$, Alzheimer's disease; $A L$, amyloid immunoglobulin light chains; apo, apoliprotein; ATTR, amyloid transthyretin; HPLC, high performance liquid chromatography; PVDF, polyvinyl difluoride; SAA, serum amyloid A protein; SDS, sodium dodecyl sulfate; SDS-PAGE, sodium dodecyl sulfate polyacrylamide ge electrophoresis; TFA, trifluoroacetic acid; TTR, transthyretin 
hereditary non-neuropathic systemic amyloidosis. ${ }^{7}$ Purification and biochemical analysis of amyloid, together with its histochemical and immunohistochemical examinations, are also important in studies of the still poorly understood pathogenesis of amyloid related diseases.

Most information on the structure of different amyloid fibril proteins has been obtained by using macropurification techniques suitable for the isolation of these proteins from large amounts of tissue obtained at necropsy. ${ }^{8-10}$ The traditionally used water solubilisation method involves multiple water extraction and centrifugation steps followed by precipitation of amyloid fibrils by salts. ${ }^{8}$ This technique enables amyloid fibrils to be prepared from 10-30 g of postmortem material containing either AA, AL, ATTR, or other proteins found in systemic amyloidoses. The classic $\mathrm{A} \beta$ isolation methods involve physical separation of cortical plaques/vessels by density gradient centrifugation, resulting in sufficient enrichment of tissue material in $A \beta$ before its extraction. ${ }^{9}{ }^{10}$ Further purification of amyloid proteins obtained by macropreparative techniques is usually accomplished by size exclusion chromatography. However, such extensive manipulation with tissue becomes impractical if only milligram quantities of starting tissue material are available. ${ }^{1}$ Furthermore, the classic extraction and purification techniques have been developed for the isolation of amyloid proteins from fresh, but not from formalin fixed, tissues. Because formalin fixed tissues are commonly used in histological studies, they are more readily available than fresh tissues. Thus, new methodological approaches, including the search for appropriate extraction solvents and separation strategies, are needed to design efficient procedures for the small scale isolation and purification of amyloid proteins.

Here, we describe the microtechniques developed for and applied to the extraction and purification of different amyloid proteins from small specimens of fresh and formalin fixed tissues, and demonstrate the applicability of these techniques for the biochemical analysis of amyloid proteins found in different clinical forms of amyloidosis and in experimental small animal models.

\section{GENERAL}

The methodological approaches used for the microextraction and purification of amyloid proteins vary in different laboratories, and sometimes it might be unclear (especially for the researcher less experienced in this specific field) how to select the appropriate methodology for the case under study. This is in contrast to classic large scale techniques, where there are clear cut guidelines for amyloid protein purification. Therefore, to overcome this problem, we have classified the existing microtechniques-first, according to the extraction solvent used, and second, according to the purification technique applied. Furthermore, the advantages and disadvantages of these new microtechniques have been outlined by taking into consideration the tissue type (formalin fixed or unfixed) and size, amyloid type, and amyloid content in the sample.

\section{MICROEXTRACTION}

\section{Fresh tissue}

Several microextraction procedures have been developed and applied to recover amyloid proteins from milligram to gram quantities of fresh frozen tissue. Tissues were usually homogenised and washed with buffered saline before the extraction procedure; in some cases, tissue homogenates were digested with collagenase and DNase ${ }^{11}{ }^{12}$ or defatted. ${ }^{13-16}$ A rapid water extraction procedure was described and used to obtain amyloid fibrils in their native state. ${ }^{17}$ In contrast, other micromethods have been developed that use denaturing conditions. Because most amyloid proteins are soluble in $6 \mathrm{M}$ guanidine hydrochloride solution, these proteins were frequently extracted using this denaturant. ${ }^{13-16} 18{ }^{19}$ In several reports, formic acid was used to recover $\mathrm{A} \beta, \mathrm{AL}$, and ATTR from small fresh tissue specimens. ${ }^{11}{ }^{12}{ }^{20}$ It was found that AA, AL, ATTR, and some more soluble $A \beta$ species could also be extracted with a milder solvent, namely: $20 \%$ acetonitrile $/ 0.1 \%$ trifluoroacetic acid (TFA). ${ }^{12} 21-34$

\section{Formalin fixed tissue}

Formalin, like other aldehyde based fixatives, forms intermolecular and intramolecular crosslinks, which might complicate the subsequent extraction of proteins from fixed tissues. However, several extraction procedures have been developed and found to be helpful in overcoming the difficulties related to the high insolubility of proteins present in formalin fixed paraffin wax embedded tissues. Incubation of the dewaxed amyloid laden fixed tissues in a standard 3\% sodium dodecyl sulfate (SDS) electrophoresis buffer at $90^{\circ} \mathrm{C}$ for five minutes led to the solubilisation of AA, but not other amyloid proteins, (such as $\mathrm{AL}, \mathrm{ATTR}$, and $\mathrm{A} \beta_{2}$ microglobulin). ${ }^{35}{ }^{36}$ Extraction with $2.5 \%$ SDS and $8 \mathrm{M}$ urea containing electrophoresis sample buffer at $90^{\circ} \mathrm{C}$ for 15 minutes enabled the recovery of $\mathrm{AL}, \mathrm{A} \beta$, and ATTR proteins. ${ }^{37}{ }^{38}$ Because no proteins were detected when the same extraction technique was applied to amyloid free formalin fixed tissues, it was proposed that amyloids, in contrast to other tissue proteins, "survive" formalin fixation. The resistance of amyloids to crosslinking could be related to the deposition of amyloids in densely packed aggregates with a $\beta$ pleated sheet conformation, which could prevent the infiltration of formalin and crosslinking. ${ }^{37}{ }^{38}$ However, other studies found that incubation of formalin fixed samples with $2 \%$ SDS containing buffers at high temperatures for a longer period of time resulted in the extraction of "non-amyloid" proteins, such as E-cadherin, $\beta$-catenin, and cyclin Dl. ${ }^{39}$ In fact, the recovery of these proteins increased significantly as the temperature increased: the highest recoveries were obtained by incubating the samples at $100^{\circ} \mathrm{C}$ for 20 minutes, followed by incubation at $60^{\circ} \mathrm{C}$ for two hours. It was suggested that the prolonged exposure of a fixed sample to high temperature might lead to the dissociation of crosslinking. ${ }^{39}$ Thus, it appears that although the $\beta$ pleated sheet configuration could be an important structural factor preserving the chemical integrity of amyloids, the experimental extraction conditions are crucial for the disruption of the existing crosslinks.

"The resistance of amyloids to crosslinking could be
related to the deposition of amyloids in densely packed
aggregates with a $\beta$ pleated sheet conformation, which
could prevent the infiltration of formalin and
crosslinking"

In some other studies, formalin fixed tissues were extracted using either formic acid or guanidine salts. Incubation of the dewaxed fixed tissues with formic acid overnight at room temperature allowed the solubilisation of the $A \beta^{40}$ and $\mathrm{AL}^{1141}$ proteins. In a recent study performed with a large number of fixed specimens $(n=49)$, different types of amyloid proteins were extracted by incubation in $6 \mathrm{M}$ guanidine solutions over 24 to 72 hours at $37^{\circ} \mathrm{C}^{42}$

\section{ELECTROPHORETIC SEPARATION AND ANALYSIS}

SDS polyacrylamide gel electrophoresis (SDS-PAGE) based western blotting and microsequencing is a simple and very frequently used approach to separate and analyse the microextracted amyloid proteins. The amyloid material extracted either by a water extraction procedure or by SDS containing buffers can be directly applied to SDS gels; formic acid and acetonitrile/TFA tissue extracts have to be dried, redissolved in sample buffer, and then run electrophoretically. 
Guanidine extracted material must be extensively dialysed before SDS-PAGE (because SDS precipitates in the presence of guanidine salts). In fact, the purification of guanidine extracted amyloid proteins is performed mainly by chromatographic means, as described in the following section. Our experience working with fresh tissues showed that for direct electrophoretic examination of crude tissue extracts, volatile extraction solvents are preferable, especially when manipulating extremely small amounts of available tissue. Such solvents can be removed by lyophilisation or by Speed-Vac drying without the need for dialysis, and the proteins could be easily re-extracted, thus increasing the recovery of amyloid.

\section{Fresh tissue}

In some reports, western blotting and microsequencing techniques were effectively used to characterise amyloid recovered from tissues by formic acid extraction. AL $\lambda$-II deposits were identified in the ureteral tissue of a patient with localised ureteral amyloidosis. ${ }^{11}$ TTR deposits of human origin were revealed in kidneys of mice transgenic for wild-type human transthyretin. ${ }^{12}$

Acetonitrile/TFA extraction followed by western blotting was used to determine the type of amyloid proteins present in very small amounts of diagnostic biopsy samples, including those of the spleen, liver, heart, thyroid, and skin ${ }^{25}$ and in fine needle fat aspirates. ${ }^{31}$ Such methods might contribute to the precise diagnosis of disease, and are particularly useful in cases where the data obtained by common immunohistochemical techniques are unexpected or questioned. Western blot analysis of acetonitrile/TFA extracts obtained from milligram amounts of $\mathrm{AD}$ brain tissue was used for $\mathrm{A} \beta$ detection ${ }^{26}$; this assay was used to distinguish between $\mathrm{AD}$ and other dementias. ${ }^{30}$ The same microextraction technique was used in the examination of skin biopsy specimens taken from patients with localised skin amyloidosis ${ }^{28}$ a disorder where the chemical nature of the amyloid fibril protein has not yet been identified. The deposition of full length apolipoprotein E (apoE) and its fragment was revealed, indicating the importance of these minor components in amyloid formation. Western blot analysis of amyloids microextracted with acetonitrile/TFA was used to study biopsy specimens taken from patients with cardiac and larynx amyloidosis. ${ }^{32}$ This study revealed a rare case showing colocalisation of two different amyloid types-ATTR and a new variant of apoA-I. In studies where the acetonitrile/ TFA extracts contained sufficient amounts of amyloid, the electrophoresed proteins were successfully sequenced after they were transferred to polyvinyl difluoride (PVDF) membranes. ${ }^{12} 232729$ Such a technique has been applied to study the fibrillar (amyloid) and non-fibrillar (non-amyloid) deposits coexisting in the same patient with $\mathrm{B}$ cell proliferative disease. ${ }^{27}$ It was shown that both types of deposits had very similar molecular masses and identical $\mathrm{N}$-terminal sequences belonging to the immunoglobulin light chain variable region of the $\mathrm{k}$-IV subgroup. The acetonitrile/TFA microextraction technique followed by western blotting, ${ }^{12}{ }^{23}$ amino acid sequencing, ${ }^{12}{ }^{23}$ and mass spectral analysis ${ }^{12}$ has also been used to study small animal models of experimentally induced AA amyloidosis, $^{23}$ senile systemic amyloidosis, ${ }^{12}$ and Down's syndrome neuropathology (C Harris-Cerruti et al. Deleterious association of elevated CuZn superoxide dismutase activity and amyloid precursor protein in a transgenic mouse model of Down syndrome neuropathology. IXth International Symposium on Amyloidosis, Budapest, 2001, abstract 9.1.10). The data obtained in such studies led to several assumptions on the mechanisms involved in the formation of amyloid fibrils. Thus, in casein induced murine amyloidosis, ${ }^{23}$ tissue deposition of both AA and its precursor the SAA2 isomer was revealed: SAA2 was detected only in the early stages of the amyloidogenic process, whereas substantial amounts of AA appeared later. It was assumed that in murine amyloidosis, the deposition of SAA2 proteins is an initial step in fibril formation, which is afterwards followed by SAA processing to AA. Similar to the case of combined light chain deposition disease and AL amyloidosis, ${ }^{27}$ the presence of both fibrillar and non-fibrillar human TTR was revealed in mice transgenic for wild-type human TTR. ${ }^{12}$ Both types of TTR deposits contained intact human TTR monomers with no evidence of proteolysis or co-deposition of murine TTR. It was found that the non-fibrillar proteins were deposited before the appearance of fibrils, thus suggesting that the non-amyloid deposits represent a precursor of the fibril.

\section{Fixed tissue}

Western blotting and microsequencing techniques were used to study amyloid proteins microextracted from fixed tissues with SDS containing buffers $\mathrm{s}^{36-38}$ and formic acid..$^{12} 41$ The analysis of formic acid extracted material allowed the identification of $\mathrm{A} \beta$ proteins in the brain of a patient with $\mathrm{AD} .{ }^{40}$ Formic acid extraction was also useful in identifying amyloid deposits consisting of $\lambda$-III immunoglobulin light chain fragments in ureteral tissue ${ }^{12}$ and immunoglobulin light chain $\lambda$ type deposits in a case of amyloidosis of the urinary bladder. ${ }^{41}$ In other studies, where fixed tissues were extracted with $2 \%$ SDS/8M urea containing buffers, amino acid sequence analysis revealed AL $\lambda$ deposits in the leptomeningeal blood vessels of a patient with cerebral amyloidosis, ${ }^{37}$ ATTR in the heart of a patient with systemic senile amyloidosis, ${ }^{38}$ and AL- $\kappa$ in the spleen of a patient with systemic amyloidosis. ${ }^{38}$

\section{CHROMATOGRAPHIC PURIFICATION AND ANALYSIS \\ Fresh tissue}

Gel filtration has been used to purify amyloid proteins extracted with $6 \mathrm{M}$ guanidine from relatively larger biopsy specimens. Amyloid extracts obtained from subcutaneous biopsy specimens (about $\left.\mathrm{l} \mathrm{cm}^{3}\right)^{13}$ and from intracerebral "amyloidoma" $(2 \mathrm{~g})^{15}$ were separated on a Sephacryl S-200 ${ }^{13}$ or a Sepharose 6B CL column. ${ }^{15}{ }^{16}$ Proteins were eluted with guanidine containing buffer, dialysed, lyophilised, and subjected to amino acid sequence analysis. These studies allowed the identification of the Alk-I, ${ }_{1}^{13}$ AL $\lambda$ ( subgroup III or IV), ${ }^{14}$ and Alא-IV $\mathrm{IV}^{16}$ proteins.

"Reversed phase high performance liquid
chromatography has not gained wide application in
the analysis of AA, AL, ATTR, and other proteins
present in the tissues of patients with systemic
amyloidosis"

Although reversed phase high performance liquid chromatography (HPLC) is efficiently used for the micropurification of proteins in different fields of biology and medicine, this technique has not gained wide application in the analysis of AA, AL, ATTR, and other proteins present in the tissues of patients with systemic amyloidosis. In fact, reversed phase HPLC on Lichrosorb RP-18 ( $10 \mu \mathrm{m}$ particle size, $250 \times 4.6 \mathrm{~mm}$ internal diameter; Knauer, Berlin, Germany) and on Vydac $218 \mathrm{TP}(5 \mathrm{~mm}$ particle size, $300 \AA$ pore diameter, $250 \times 4.6 \mathrm{~mm}$ internal diameter; Alltech, Deerfield, Illinois, USA) columns was effective for the purification of $\mathrm{AA}^{43}{ }^{44}$ but not for AL or ATTR. ${ }^{43}{ }^{45}$ Reversed phase HPLC was used to purify $\mathrm{A} \beta$ proteins microextracted with formic acid from $\mathrm{AD}$ brain tissue. ${ }^{20}$ In this study, tissue homogenates were washed with SDS containing buffers before $A \beta$ extraction, so that the HPLC purified $A \beta$ material represented the SDS insoluble $A \beta$ fraction. In our study, which aimed to recover the total amount of $\mathrm{A} \beta$ deposits, the $\mathrm{AD}$ tissue homogenates were washed in the absence of this detergent and extracted using acetonitrile/TFA and formic acid sequentially. ${ }^{34}$ Although the extracted 
material contained large amounts of $\mathrm{A} \beta$ proteins, the application of reversed phase HPLC alone was insufficient for the purification of these proteins (B Kaplan, 1999, unpublished data).

Size exclusion HPLC in SDS containing buffer (Bio-Sil TSK-125, $5 \mu \mathrm{m}$; Bio-Rad, Richmond, California, USA) was applied to study AA, AL, and ATTR proteins microextracted with acetonitrile/TFA. ${ }^{21}$ However, this technique resulted only in partial purification of amyloid proteins, as assessed from the electrophoretic examination of the HPLC fractions obtained. Efficient purification of low molecular mass amyloid $(<12 \mathrm{kDa})$, such as AA and small AL proteins, was achieved on a size exclusion HPLC column in aqueous organic solvent. ${ }^{46}$ Using this technique, amyloid protens were microextracted with $20 \%$ acetonitrile/0.1\% TFA from fresh frozen samples and further purified on a Bio-Sil TSK column equilibrated with the same solvent. ${ }^{21}$ Unfortunately, this technique was not useful for studying the higher molecular mass amyloid proteins (>12 kDa). It should be noted that elution with acetonitrile/TFA resulted in an aberrant size exclusion behaviour on the Bio-Sil TSK column, presumably because of the interaction of the protein with the residual silanols on the silica based HPLC columns. This might explain why the larger amyloid proteins were poorly resolved by this technique..$^{216}$

\section{Fixed tissue}

In most studies, reversed phase HPLC was used for the purification of fixed amyloid proteins recovered from tissues by the guanidine extraction technique. ${ }^{142}$ Briefly, amyloid proteins extracted with $6 \mathrm{M}$ guanidine hydrochloride containing buffer were reduced and alkylated, and then run on an Aquapore 300 $\mathrm{C}_{8}(30 \times 4.0 \mathrm{~mm})$ column (Brownlee Column; Perkin Elmer, Norwalk, Connecticut, USA). The HPLC purified material was sequenced, thus allowing identification of nine types of amyloid proteins (including AA, AL, ATTR, Alys, and ApoA-I) found in different biopsy samples (for example, spleen, kidney, liver, heart, abdominal fat, and colon). Recently, this technique was used to study formalin fixed heart tissue samples from a patient with senile systemic amyloidosis, where ATTR was found to be co-deposited with a minor amyloid constituent, apoA-IV. ${ }^{47}$ In this study, the ability of apoA-IV to enhance amyloid formation was demonstrated. Thus, guanidine extraction from formalin fixed tissues, followed by separation on reversed phase HPLC columns and chemical analysis of purified amyloid proteins, is a valuable technique for the precise diagnosis of amyloid associated disorders and could aid in the examination of the mechanisms of amyloid formation in these diseases.

\section{COMBINED PURIFICATION TECHNIQUES}

Although the number of separation steps should be as small as possible in small scale purification design, it is not always possible to purify microextracted amyloid proteins in a single separation step. We faced such a situation in the analysis of fresh frozen (non-fixed) tissue extracts where the content of amyloid proteins was small and the contamination by other co-extracted tissue proteins was great. ${ }^{45}$ In fact, micropreparative slab gel SDS electrophoresis allows the efficient separation of proteins on the basis of their differences in molecular mass, but in using this method separated amyloid proteins might still be contaminated by other proteins of the same electrophoretic mobility. In cases where the amount of the available biopsy material was sufficient (such as subcutaneous fat biopsies ${ }^{13}{ }^{14}$ ), purification was achieved by combining gel filtration on a $800 \times 9 \mathrm{~mm}$ internal diameter Sephacryl S-2000 HR (Pharmacia, Uppsala, Sweden) column with reversed phase HPLC on a $250 \times 4.6 \mathrm{~mm}$ VYDAC 214 TPS (Hesperia, California, USA) column. However, such relatively large gel filtration columns are less practical when analysing the extracts obtained from smaller tissue samples. Although the use of size exclusion HPLC columns could be more appropriate for small samples, our experience showed that in many instances the resolution of amyloid proteins obtained by size exclusion HPLC was less efficient than when micropreparative slab gel SDS electrophoresis was used. ${ }^{45}$

We developed a technique that combines slab gel SDS electrophoresis (SDS-PAGE) with subsequent reversed phase HPLC, ${ }^{44} 49$ and recently adapted it for the purification of AA, $\mathrm{AL}, \mathrm{ATTR}$, and $\mathrm{A} \beta$ proteins microextracted from non-fixed tissues. ${ }^{33450}$ Using this technique, the electrophoresed proteins were transferred to PVDF membranes, then eluted from the membranes, and finally applied to reversed phase HPLC. We found that the elution from PVDF with TFA/acetonitrile/ water $(3 / 4 / 3, \mathrm{vol} / \mathrm{vol})$ solvent allowed efficient recovery of the $\mathrm{AA}, \mathrm{AL}$, ATTR, and A $\beta$ proteins from the PVDF membranes, and was compatible with the subsequent reversed phase HPLC separation. A consecutive SDS-PAGE and reversed phase HPLC technique was used for the purification of $A \beta$ from crude AD brain tissue extracts. ${ }^{345}$ It allowed the amyloid proteins to be separated electrophoretically from higher and lower molecular mass tissue components, and then purified by reversed phase HPLC from the contaminants that had similar molecular masses but different retention times on the column.

\section{CONCLUDING REMARKS}

The strategy for the small scale purification of amyloid proteins depends largely on the type of tissue sample (fresh or formalin fixed), sample size, amyloid content of the tissue, and its chemical nature. Aqueous acetonitrile/TFA solvent was effectively used for the microextraction of different amyloid proteins from non-fixed tissues, although it was unsuitable for the extraction of amyloid proteins from formalin fixed tissues, where harsher treatments were needed to achieve amyloid solubilisation. Reversed phase HPLC was used successfully for the purification and analysis of different types of amyloid proteins recovered from formalin fixed tissues. However, in the examination of fresh tissues, purification by HPLC was efficient only for some amyloid proteins, depending on their chemical type and molecular mass. SDS-PAGE based western blotting appears to be a more universal approach for the initial analysis of amyloid proteins microextracted from non-fixed tissues. It allows the type, molecular mass, and amount of amyloid to be determined. Where the amount of amyloid is sufficient, an SDS-PAGE based microsequencing technique could provide information on the primary amyloid protein structure. When the amount of amyloid is small and contamination by other coextracted tissue proteins is high, the combined use of electrophoretic and HPLC techniques seems to be promising.

\section{ACKNOWLEDGEMENTS}

Thanks to Mrs L Gans (Heller Institute of Medical Research, Sheba Medical Center, Tel-Hashomer, Israel) for helpful assistance in the preparation of this manuscript.

\section{Authors' affiliations}

B Kaplan, S Shtrasburg, M Pras, Heller Institute of Medical Research, Sheba Medical Centre, Tel Hashomer 52621, Israel

\section{REFERENCES}

1 Kaplan B, Hrncic R, Murphy CL, et al. Microextraction and purification techniques applicable to the characterization of amyloid proteins in minute amounts of tissue. Methods Enzymol 1999;309:67-81.

2 Khan MS, Falk RH. Amyloidosis. Postgrad Med J 2001;77:686-91.

3 Rocken C, Shakespeare A. Pathology, diagnosis and pathogenesis of AA amyloidosis. Virchows Arch 2002;440:114-22.

4 Gertz MA, Rajkumar FV. Primary systemic amyloidosis. Curr Treat Options Oncol 2002;3:261-71.

5 Pras $M$, Prelli F, Franklin EC, et al. Primary structure of amyloid prealbumin variant in familial polyneuropathy of Jewish origin. Proc Nat Acad Sci U S A 1983;80:539-42. 


\section{Take home messages}

- Amyloidosis is a heterogenous group of diseases associated with the deposition of chemically distinct amyloid fibril proteins and the precise chemical and immunochemical identification of these proteins has diagnostic and therapeutic importance

- The strategy for the small scale purification of amyloid proteins depends largely on the type of tissue sample (fresh or formalin fixed), sample size, amyloid content of the tissue, and its chemical nature

- Guanidine hydrochloride and aqueous acetonitrile/ trifluoroacetic acid have been used for the microextraction of different amyloid proteins from fresh tissues

- Harsher treatments (such as sodium dodecyl sulfate (SDS)/ SDS and urea at high temperatures) are needed for the extraction of amyloid proteins from formalin fixed tissues

- Reversed phase high performance liquid chromatography (HPLC) can be used for the purification and analysis of different types of amyloid proteins extracted from formalin fixed tissues

- However, SDS polyacrylamide gel electrophoresis (PAGE) based western blotting seems to be a better approach for the initial analysis of amyloid proteins microextracted from fresh tissues because it allows the type, molecular mass, and amount of amyloid to be determined

- Where the amount of amyloid is sufficient, an SDS-PAGE based microsequencing technique could provide information on the primary amyloid protein structure

- If only small amounts of highly contaminated amyloid are present, the combined use of electrophoretic and HPLC techniques may be useful

6 Prelli F, Pras M, Frangione B. Degradation and deposition of amyloid AA fibrils are tissue specific. Biochemistry 1987;26:8251-6.

7 Lachmann HJ, Chir B, Booth DR, et al. Misdiagnosis of hereditary amyloidosis as $\mathrm{AL}$ (primary) amyloidosis. N Engl J Med 2002;346:1786-91

8 Pras $M$, Schubert M, Zucker-Franklin D, et al. The characterization of soluble amyloid prepared in water. J Clin Invest 1968:47:924-33.

9 Glenner GG, Wong CW. Alzheimer's disease: initial report of the purification and characterization of a novel cerebrovascular amyloid protein. Biochem Biophys Res Commun 1984;120:885-90.

10 Roher AE, Kuo YM. Isolation of amyloid deposits from brain. Methods Enzymol 1999:309:58-69.

11 Castano M, Prelli F, Morelli L, et al. Immunoglobulin lambda light chains are precursors of ureteral localized amyloidosis: a micromethod for extraction of amyloid. Amyloid 1997;4:253-8.

12 Teng $M$, Yin J, Vidal R, et al. Amyloid and nonfibrillar deposits in mice transgenic for wild-type human transthyretin: a possible model for senile systemic amyloidosis. Lab Invest 2001;81:385-96.

13 Westermark P, Benson L, Juul J, et al. Use of subcutaneous abdominal fat biopsy specimen for detailed typing of amyloid fibril protein AL by amino acid sequence analysis. J Clin Pathol 1989:42:817-19.

14 Forsberg $\mathbf{A H}$, Sletten K, Benson L, et al. Abdominal fat biopsy for characterization of the major amyloid fibril proteins by amino acid sequence. In: Natvig JB, Forre O, Husby G, et al, eds. Amyloid and amyloidosis 1990. Norwell, MA: Kluver Academic, Dordrecht, 1990:797-800.

15 Eriksson L, Sletten K, Benson L, et al. Tumor-like localized amyloid of brain is derived from immunoglobulin light chain. Scand J Immunol 1993;37:623-6

16 Olsen KE, Sletten K, Westermark P. Extended analysis of AL-amyloid protein from abdominal wall subcutaneous fat biopsy: kappa IV immunoglobulin light chain. Biochem Biophys Res Commun 1998;245:713-16.

17 Tennent GA. Isolation and characterization of amyloid fibrils from tissue. Methods Enzymol 1999;309:26-47.

18 Olsen KE, Sletten K, Westermark P. The use of subcutaneous fat tissue for amyloid typing by enzyme-linked immunosorbent assay. Am J Clin Pathol 1999;111:355-62.

19 Hazenberg BPC, Limburg PC, Bijzet J, et al. A quantitative method for detecting deposits of amyloid A protein in aspirated fat tissue of patients with arthritis. Ann Rheum Dis 1999:58:96-102.

20 Mori H, Takio K, Ogawara M, et al. Mass spectroscopy of purified amyloid $\beta$ protein in Alzheimer's disease. J Biol Chem 1992;267: 17082-6.

21 Kaplan B, German G, Pras M. Isolation and characterization of amyloid proteins from milligram amounts of amyloid-containing tissue. J Liq Chromatogr 1993; 16:2249-68.
22 Kaplan B, German G, Ravid M, et al. Determination of amyloid type by ELISA using milligram amounts of tissue. Clin Chim Acto 1994;229:174-9.

23 Yakar S, Kaplan B, Livneh A, et al. Direct evidence for SAA deposition in tissues during murine amyloidogenesis. Scand J Immunol 1994:40:653-8.

24 Yakar S, Kaplan B, German G, et al. Quantification of tissue amyloid content in AA amyloidosis by inhibition ELISA. Amyloid 1995;2:167-72.

25 Kaplan B, Yakar S, Kumar A, et al. Immunochemical characterization of amyloid in diagnostic biopsy tissues. Amyloid 1997:4:80-6.

26 Kaplan B, Martin B, Yakar S, et al. A simple procedure of immunochemical detection of amyloid $\beta$ proteins using milligram amounts of brain tissues of patients with Alzheimer's disease. In: Fisher A, Yoshida M, Hanin I, eds. Progress in Alzheimer's and Parkinson's diseases. New York: Plenum Press, 1998:823-8.

27 Kaplan B, Vidal R, Kumar A, et al. Amino-terminal identity of co-existent amyloid and non-amyloid immunoglobulin light chain deposits. Clin Exp Immunol 1997; 110:427-78

28 Furumoto $\mathbf{H}$, Shimizu T, Asagami $C$, et al. Apolipoprotein $\mathrm{E}$ is present in primary localized cutaneous amyloidosis. J Invest Dermatol 1998;111:417-21.

29 Rostango A, Vidal R, Kaplan B, et al. pH-dependent fibrillogenesis of $\mathrm{V}$ kappa III Bence Jones protein. Br J Haematol 1999;107:835-43.

30 Kaplan B, Haroutunian V, Koudinov A, et al. Biochemical assay for amyloid $\beta$ deposits to distinguish Alzheimer's disease from other dementias. Clin Chim Acta 1999;280:147-59.

31 Kaplan B, Vidal R, Ghiso J, et al. Immunochemical microanalysis of amyloid proteins in diagnostic fine needle fat aspirates. Am J Clin Pathol 1999:112:403-7.

32 de Sousa MM, Vital C, Ostler D, et al. Apolipoprotein Al and transthyretin as components of amyloid fibrils in a kindred with apoAlleu 178His amyloidosis. Am J Pathol 2000;156:1911-17.

33 Kaplan B, Murphy CL, Ratner V, et al. Micro-method to isolate and purify amyloid proteins for chemical characterization. Amyloid 2001;8:22-9.

34 Kaplan B, Pras M. Combined use of micro-preparative gel electrophoresis and reversed phase high performance liquid chromatography for purification of amyloid $\beta$ proteins. J Chromatogr $B$ Analyt Technol Biomed Life Sci 2002;769:363-70.

35 Shtrasburg S, Pras $M$, Langevitch $P$, et al. Demonstration of AA-protein in formalin-fixed, paraffin-embedded tissues. Am J Pathol 1982;106:141-4.

36 Shtrasburg $S$, Livneh A, Pras $M$, et al. Detection of serum amyloid A-derived proteins in formalin-fixed paraffin-embedded tissues. Reliability of the method and expansion of its spectrum. Am J Clin Pathol 1997; 108:289-94.

37 Layfield R, Baily K, Lowe J, et al. Extraction and protein sequencing of immunoglobulin light chain from formalin-fixed cerebrovascular amyloid deposits. J Pathol 1996;180:455-9.

38 Layfield R, Bailey K, Dineen R, et al. Application of formalin fixation to the purification of amyloid proteins. Anal Biochem 1997;253:142-4.

39 Ikeda K, Monden T, Kanoh T, et al. Extraction and analysis of diagnostically useful proteins from formalin-fixed, paraffin-embedded tissue sections. J Histochem Cytochem 1998:46:397-403.

40 Coria F, Prelli F, Castano EM, et al. $\beta$ Protein deposition: a pathogenetic link between Alzheimer's disease and cerebral amyloid angiopathies. Brain Res 1988;463:187-91

41 Livneh A, Shtrasburg S, Martin B, et al. Light chain amyloidosis of the urinary bladder. A site restricted deposition of an externally produced immunoglobulin. J Clin Pathol 2001;54:920-3.

42 Murphy CL, Eulitz M, Hrncic R, et al. Chemical typing of amyloid proteins contained in formalin-fixed paraffin-embedded biopsy specimens. Am J Clin Pathol 2001;116:135-42.

43 Kaplan B, Pras M. Preparative fractionation of amyloid proteins on a microgram scale by high performance liquid chromatography. Clin Chim Acta 1987; 163:199-205

44 Kaplan B, Pras M, Ravid M. Isolation and purification of amyloid protein A by sodium dodecyl sulphate polyacrylamide gel electrophoresis and reverse phase high performance liquid chromatography. J Chromatog 1992;573:17-22.

45 Kaplan B. Application of polyacrylamide slab gel electrophoresis in small scale purification of amyloid proteins. Anal Chim Acto 1998:372:161-72.

46 Kaplan B, Pras M. Separation of amyloid proteins by size exclusion chromatography in aqueous organic mobile phase. J Liq Chromatogr 1992;15:2467-86

47 Bergstrom J, Murphy C, Eulitz M, et al. Codeposition of apolipoprotein A-IV and transthyretin in senile systemic (ATTR) amyloidosis. Biochem Biophys Res Commun 2001;285:903-8.

48 Kaplan B, Pras M. Separation of proteins by using consecutively sodium dodecyl sulphate polyacrylamide gel electrophoresis and reversed phase HPLC. Biomed Chromatogr 1991;5:86-9.

49 Kaplan B, Yakar S, Balta Y, et al. Isolation and characterization of two major amyloid $A$ isotypes SAA1 and SAA2 from the acute phase plasma of mice. J Chromatogr B Biomed Sci Appl 1997;704:69-76.

50 Kaplan B. Consecutive sodium dodecyl sulphate gel electrophoresis and reversed phase high performance liquid chromatography. Applications to the micro-purification and analysis of proteins, peptides and related compounds. Current Topics in Analytical Chemistry 2001;2:160-9. 